\title{
Carbide-Free Bainite Transformations Above and Below Martensite Start Temperature Investigated by In-Situ High-Energy X-Ray Diffraction
}

\author{
CÉCILE RAMPELBERG @i], ${ }^{1,2,3}$ SÉBASTIEN YVES PIERRE ALLAIN ®i], ${ }^{1,4}$ \\ GUILLAUME GEANDIER, 1,5 JULIEN TEIXEIRA (1), ${ }^{1,6}$ \\ FLORIMONDE LEBEL, ${ }^{1,7}$ and THOMAS SOURMAIL (1) ${ }^{2,8}$
}

1.-UMR CNRS UL 7198, Institut Jean Lamour, Campus ARTEM, 2 Allée André Guinier, 54000 Nancy, France. 2.-Swiss Steel Group, Ascometal CREAS, BP 70045, Hagondange, France. 3.—e-mail: cecile.rampelberg@univ-lorraine.fr. 4.-e-mail: sebastien.allain@univ-lorraine.fr. 5.—e-mail: guillaume.geandier@univ-lorraine.fr. 6.-e-mail: julien.teixeira@univ-lorraine.fr. 7.-e-mail: florimonde.lebel@univ-lorraine.fr. $\quad$ 8.-e-mail: thomas.sourmail@ascometal.com

Carbide-free bainitic advanced high-strength steels (AHSS) exhibits multiphase microstructures made of fine ferrite and retained austenite. The carbon partitions between these constituting phases during the bainitic transformation were studied above and below the martensite start temperature $\left(M_{\mathrm{S}}\right)$ by in-situ high-energy X-ray diffraction experiments. The time-resolved analysis of the phase fraction, austenite lattice parameter, and ferrite tetragonality offer the possibility of establishing phase-scaled consistent and precise carbon balances. In the studied steel, the carbon content in ferrite ranges between 0.1 and 0.15 wt.\% after isothermal treatments, meaning that the available carbon for austenite stabilization is reduced. The stasis conditions are close to the $T_{0}{ }^{\prime}$ criterion below $400^{\circ} \mathrm{C}$ but are not reached at higher temperatures. Our multistep experiments also prove that the transformation below $M_{\mathrm{S}}$ is very sensitive to the carbon content in austenite and auto-catalytic nucleation processes inherited from prior transformations (martensite and bainite at higher temperature). The bainitic transformation thus does not follow additivity rules.

\section{INTRODUCTION}

Carbide-free bainites (CFB) are multiphase microstructures obtained from austenite decomposition at low temperatures (typically between $450^{\circ} \mathrm{C}$ and $300^{\circ} \mathrm{C}$ ) in alloyed steels which have a high potential for industrial applications. ${ }^{1-6}$ They are made of a fine ferritic matrix with a lath morphology without carbide, retained austenite stabilized by carbon partitioning during the transformation and fresh martensite appearing during the final cooling after bainite transformation. ${ }^{1}$ Such a metastable microstructure can be obtained because the CFB transformation is displacive and incomplete. ${ }^{3,7-9}$ The high fraction of residual austenite may transform during further mechanical loading at room temperature

(Received June 4, 2021; accepted September 2, 2021;

published online September 30, 2021) (stress or strain induced transformation) and leads to a possible TRIP effect (TRansformation Induced Plasticity). ${ }^{3,10-14}$ These microstructures have been investigated for over 20 years but the criterion for the incomplete transformation phenomenon remains one of the current bones of contention in the literature. ${ }^{15}$ Diffusionless theories of bainite transformation assume a thermodynamic limit called the $T_{0}{ }^{\prime}$ line (nucleation controlled). ${ }^{13,16}$ During the transformation, the austenite gets progressively enriched by the carbon rejected by the bainitic ferrite. In the so-called diffusionless approach, at a given temperature the nucleation of new bainite units stops when the carbon concentration in austenite exceeds a critical value corresponding to the composition for which both austenite and ferrite have the same Gibbs's energy. This mechanism leads to an incomplete transformation or a stasis. The $T_{0}$ line is the locus of these critical carbon concentrations in austenite as a function of the 
temperature. Thermodynamically, the formation of bainitic ferrite without change of carbon composition is no longer possible when the $T_{0}$ temperature goes below the transformation temperature. The $T_{0}{ }^{\prime}$ curve also takes into account the elastic strain energy stored in ferrite (ca. $400 \mathrm{~J} \cdot \mathrm{mol}^{-1}$ ) in the Gibb's energy calculation, ${ }^{13}$ whereas diffusive theories consider a stagnant process (dissipative mobility of interfaces) during isothermal holding (growth controlled). ${ }^{17}$ The objective of this work was to bring new experimental evidence to feed this discussion; in particular, we aimed to establish a very precise carbon balance between phases and challenge the $T_{0}{ }^{\prime}$ criterion.

In this work, we studied the formation of CFB microstructures at different temperatures in isothermal conditions from a fully austenitic state by in-situ high-energy X-ray diffraction (HEXRD) experiments. If the transformation occurs above the martensite start temperature $\left(M_{\mathrm{S}}\right)$, the final microstructure is composed of bainite (noted B), retained austenite (noted A) and fresh martensite (noted FM). It is far more difficult to study the bainitic transformation below $M_{\mathrm{S}}$ as the martensitic transformation occurs almost instantaneously, prior to the bainitic ones. The final microstructure in that case also contains tempered martensite (TM).

In order to investigate how the initial austenite state affects the transformation below $M_{\mathrm{S}}$, two multistep treatments were designed. Instead of studying the transformation after a partial martensitic transformation, such treatments investigate it after partial bainitic or bainitic/martensitic transformations.

For such transformations, in-situ HEXRD experiments allow for simultaneous measurements of phase transformation kinetics, austenite lattice parameter changes, and evolution of bainitic phase tetragonality all along an uninterrupted isothermal treatment. In addition, minor carbide precipitation processes can be identified. ${ }^{18}$ As a consequence, a rigorous carbon balance between phases can be established, especially in isothermal conditions above $M_{\mathrm{S}}$. To the knowledge of the authors, this is the first time that such a level of consistency has been obtained between the estimation of the carbon content in austenite and the carbon kept in supersaturation in bainite. ${ }^{19}$ The microstructures after thermal treatments were also studied by scanning electron microscopy. By coupling these observations, it was possible to finely estimate the stability of retained austenite at room temperature after the different cooling schedules.

\section{EXPERIMENTAL PROCEDURE}

The studied industrial steel was produced by Ascometal $^{20}$ and has a base chemical composition of Fe-0.27C-1.5Mn-1.2Si-0.8Cr (wt.\%). The samples investigated were cylindrical with a size of $10 \mathrm{~mm}$ length and $4 \mathrm{~mm}$ diameter. Each sample was machined from the mid-radius of a hot-rolled steel $\operatorname{bar}(\varnothing 40 \mathrm{~mm})$.
The in-situ HEXRD experiments were performed on the P07 beamline at PETRA III at Deutsches Elektronen-Synchrotron (DESY), Hamburg, Germany. A synchrotron X-ray monochromatic beam $\left(500 \times 500 \mu \mathrm{m}^{2}\right)$ with high energy $(100 \mathrm{keV}$ corresponding to a wavelength $\lambda=0.123984 \AA$ ) was used to illuminate the sample and to work in transmission in a powder diffraction configuration. The high photon flux from the synchrotron source and the large 2D detector (Perkin-Elmer) with slow and fast acquisition modes, allowed collection of DebyeScherrer diffraction patterns at different rates (10 Hz or $0.3 \mathrm{~Hz}$, respectively). The sample was heated with a Bähr DIL 805 A/D dilatometer. The temperature was measured with a thermocouple welded directly onto the cylindrical specimen.

In this paper, different thermal conditions were studied: conventional isothermal holdings and multi-step conditions. Multi-step cooling sequences are a succession of isothermal holdings at different decreasing temperatures. All these thermal treatments started with an austenitic soaking at $3^{\circ} \mathrm{C} / \mathrm{s}$ up to $1150^{\circ} \mathrm{C}$ for $3 \mathrm{~min}$ leading to a prior austenite grain (PAG) size around $74 \pm 42 \mu \mathrm{m}$ : close to that achieved after hot forging of relatively large components such as automotive crankshafts, wheel hubs, etc. The transitions between all the isothermal temperature steps were performed at $50^{\circ} \mathrm{C} / \mathrm{s}$.

Figure 1a shows the temperature as a function of time schedules for isothermal conditions, with temperatures ranging between $300^{\circ} \mathrm{C}$ and $475^{\circ} \mathrm{C}$ and a holding time set at $20 \mathrm{~min}$. The investigation of bainite transformation was made below and above the $M_{\mathrm{S}}$ (martensite start temperature); the $M_{\mathrm{S}}$ of the alloy is about $350^{\circ} \mathrm{C}\left(346^{\circ} \mathrm{C}\right)$ as determined by dilatometry experiment. Calculations of the $M_{\mathrm{S}}$ in the literature, proposed by Van Bohemen ${ }^{21}$ and Barbier, ${ }^{22}$ were found to be $356^{\circ} \mathrm{C}$ and $341^{\circ} \mathrm{C}$, respectively. Those results are close, and in agreement with the one determined experimentally. Above $M_{\mathrm{S}}$ and at $M_{\mathrm{S}}$, the experiments were denoted by the letter $\mathrm{B}$ followed by the transformation temperature. At $300^{\circ} \mathrm{C}$ (below $M_{\mathrm{S}}$ ), the martensite fraction prior to bainite transition was estimated by the Koistinen-Marburger relation around 61 wt. $\%{ }^{23}$ The corresponding experiment was further denoted $\mathrm{M}+\mathrm{B} 300$. The experiments above $M_{\mathrm{S}}$ are denoted as BXXX (XXX = 350, 400, 450 or 475). Isothermal holdings were followed by cooling down to room temperature.

Figure $1 \mathrm{~b}$ shows the heat treatments corresponding to the multi-step cooling sequences discussed above. The two-step schedule consists of a first step at $400^{\circ} \mathrm{C}$ for $40 \mathrm{~s}$, followed by a second step at $300^{\circ} \mathrm{C}$ for $20 \mathrm{~min}$. During the first step, a partial bainitic transformation at $400^{\circ} \mathrm{C}$ is expected (typically $30 \mathrm{wt} . \%$ of bainite). As the stabilization of austenite is not sufficient in such conditions, a partial martensitic transformation occurs during the transition between the steps. Finally, a bainitic transformation should occur in the untransformed 

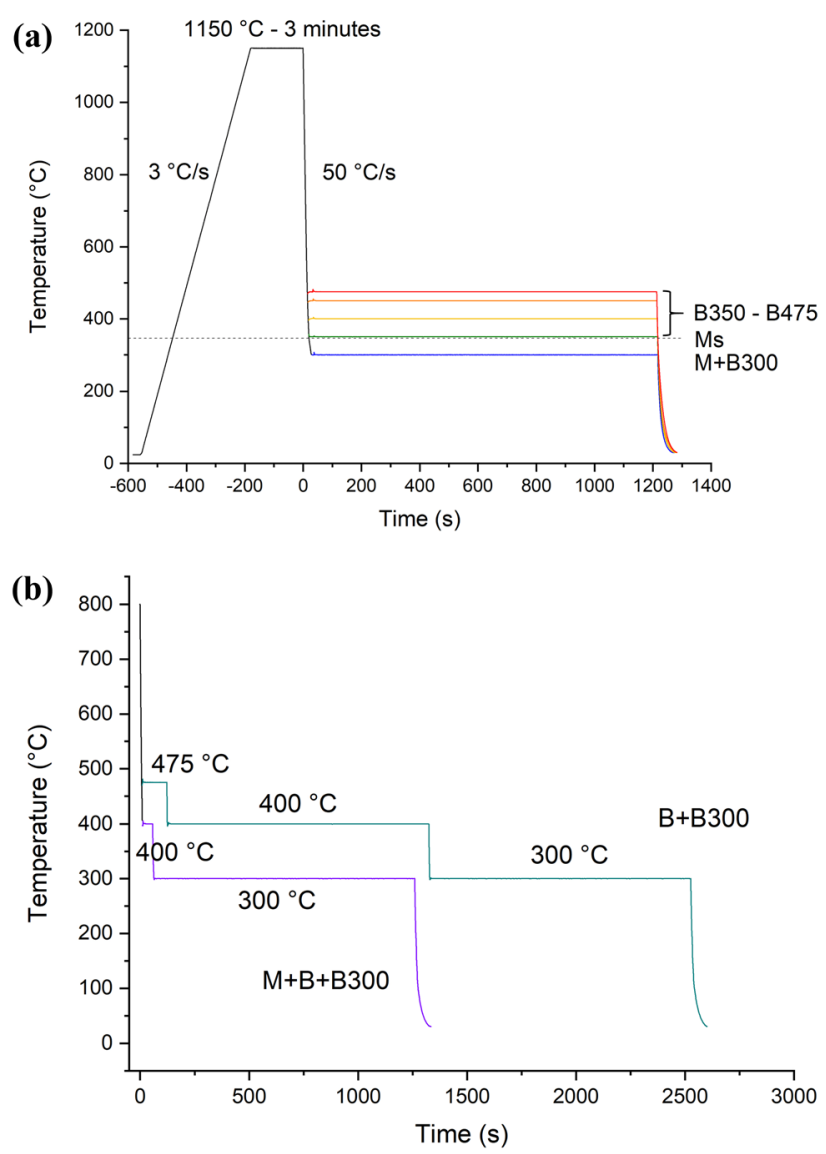

Fig. 1. Heat treatment schedules. (a) Isothermal conditions; (b) multi-step conditions.

austenite at $300^{\circ} \mathrm{C}$. The designed microstructure was composed of bainite, martensite, and bainite at $300^{\circ} \mathrm{C}$. The experiment was denoted $\mathrm{B}+\mathrm{M}+\mathrm{B} 300$ in the following.

The three-step cooling sequence aimed at studying the bainitic transformation at $300^{\circ} \mathrm{C}$, after a well-developed bainitic transformation at higher temperatures. Here, a sufficient enrichment of retained austenite is expected to avoid any martensitic transformation. It consists of a first step at $475^{\circ} \mathrm{C}$ for $115 \mathrm{~s}$ then a second step and third step at $400^{\circ} \mathrm{C}$ and $300^{\circ} \mathrm{C}$, respectively, for $20 \mathrm{~min}$ at each step. The designed microstructure is thus composed of two types of bainite and bainite at $300^{\circ} \mathrm{C}$. The experiment was denoted B + B300 in the following. As for isothermal holdings, both multi-step conditions were followed by a final cooling to room temperature with a cooling rate of $50^{\circ} \mathrm{C} / \mathrm{s}$.

The two-dimensional X-ray patterns obtained during experiments were integrated circularly with the PyFAI python library. ${ }^{24}$ Sample to detector distance and detector orthogonality to the beam was calibrated using LaB6 powder (NIST 660a). The one-dimensional diffractograms were analyzed following a Rietveld ${ }^{25}$ refinement method using FullProf. $^{26}$ The pseudo-Voigt function was used in the Rietveld refinement to simulate diffraction peaks.
In this refinement, two phases were considered: austenite with a cubic face centered structure (Fm$3 \mathrm{~m})$ and bainite and martensite with a body-centered tetragonal structure (BCT: I 4/mmm). The Rfactor was used for each phase as the indicator of the quality of simulation. ${ }^{27}$ During the present experiments, it was not possible to discriminate between these last two phases on the basis of diffraction patterns. The mass fraction of BCT phase thus corresponds to the sum of the bainite and martensite contribution. However, as they appear sequentially, their respective transformation kinetics can be identified uniquely by a metallurgical reasoning on the basis of existing knowledge.

It must be mentioned that the BCT structure systematically leads to a better adjustment than a BCC (body-centered cubic) structure. This has already been observed in previous studies by some groups. ${ }^{28-32}$ This justifies the use of a tetragonal unit cell to assess the carbon content in solid solution in bainitic ferrite (in the absence of tempered martensite, of course).

For all experiments, the mean austenitic grain size was $74 \pm 42 \mu \mathrm{m}$ at high temperature and thus the grains are large compared with the studied volume $\left(500 \times 500 \times 4000 \mu \mathrm{m}^{3}\right)$. In the two-dimensional X-ray patterns, the Debye Scherrer rings are discontinuous and exhibit many spots as a consequence, shown in Fig. 2a. These spots affect the austenite peak shapes on the 1D diffractograms shown in Fig. 2b. It is therefore impossible to determine the evolution of the austenite phase with good accuracy from the high temperature and at the very beginning of the bainite transformation. These spots jeopardize not only the correct measurement of the phase fraction but also the austenite lattice parameters. The value becomes exploitable only after a certain amount of bainite transformation. Quantification is possible after about $15 \mathrm{wt} \%$ of bainite transformation.

Figure 2c shows the two-dimensional image for the isothermal experiment at $400^{\circ} \mathrm{C}$ after the formation of 20 wt.\% bainite. The Debye Scherrer rings are still discontinuous and some spots are present and disturb the intensity. However, the position and the intensity of the peaks become insensitive to the appearance or disappearance of single spots. At the stage shown in Fig 2 d, it was considered that the determined values were meaningful and relevant. The R-factor was slightly high (around 2.0); then, as the transformation continued, the R-factor decreased.

\section{RESULTS}

\section{Kinetics of Bainite and Martensite Transformation Under Isothermal Conditions}

Figure $3 \mathrm{a}$ shows the evolution of bainite and martensite mass fractions as a function of time 

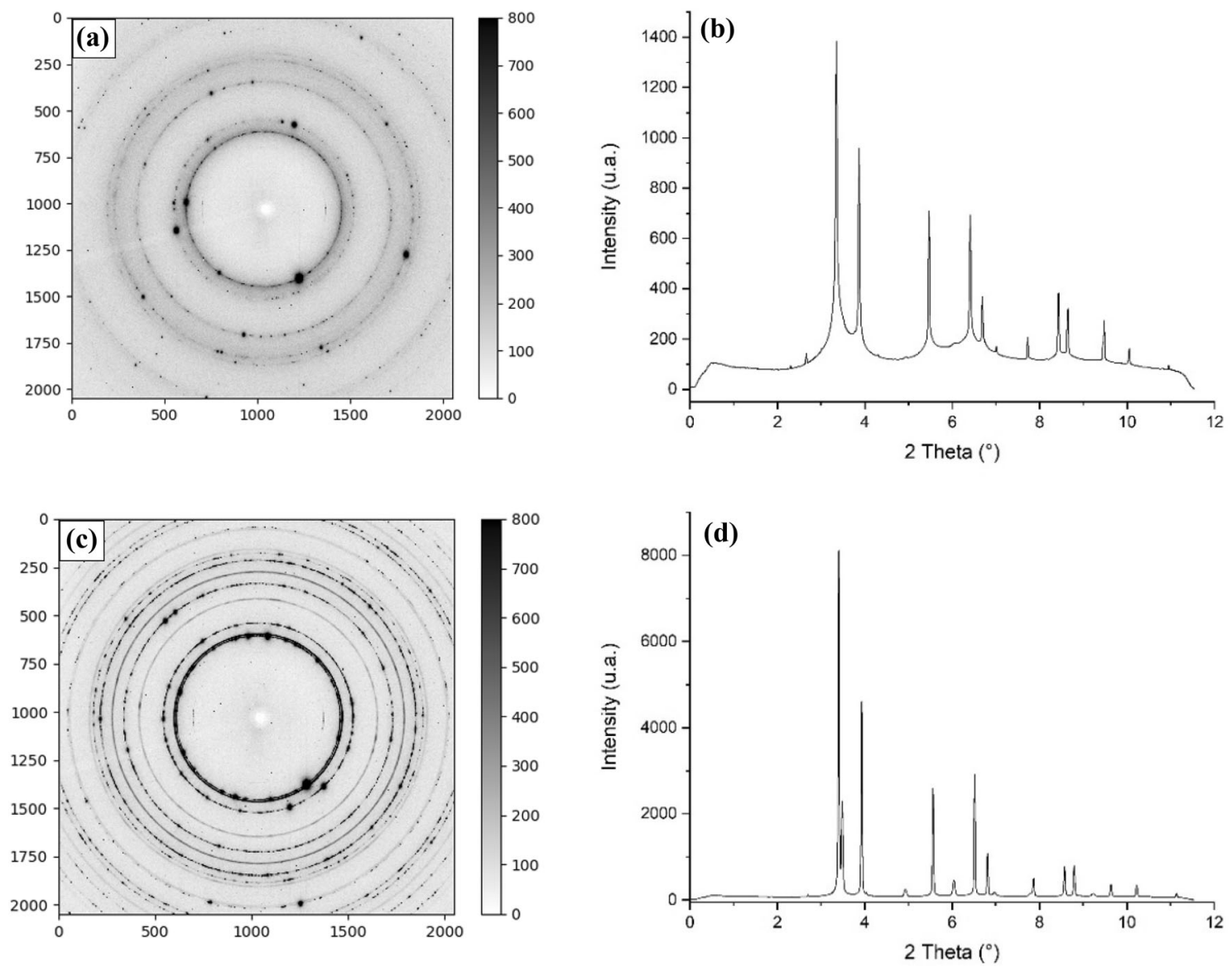

Fig. 2. 2D image (a) and 1D spectrum (b) at the end of the austenitic soaking; 2D image (c) and 1D spectrum (d) at the beginning of bainite formation.
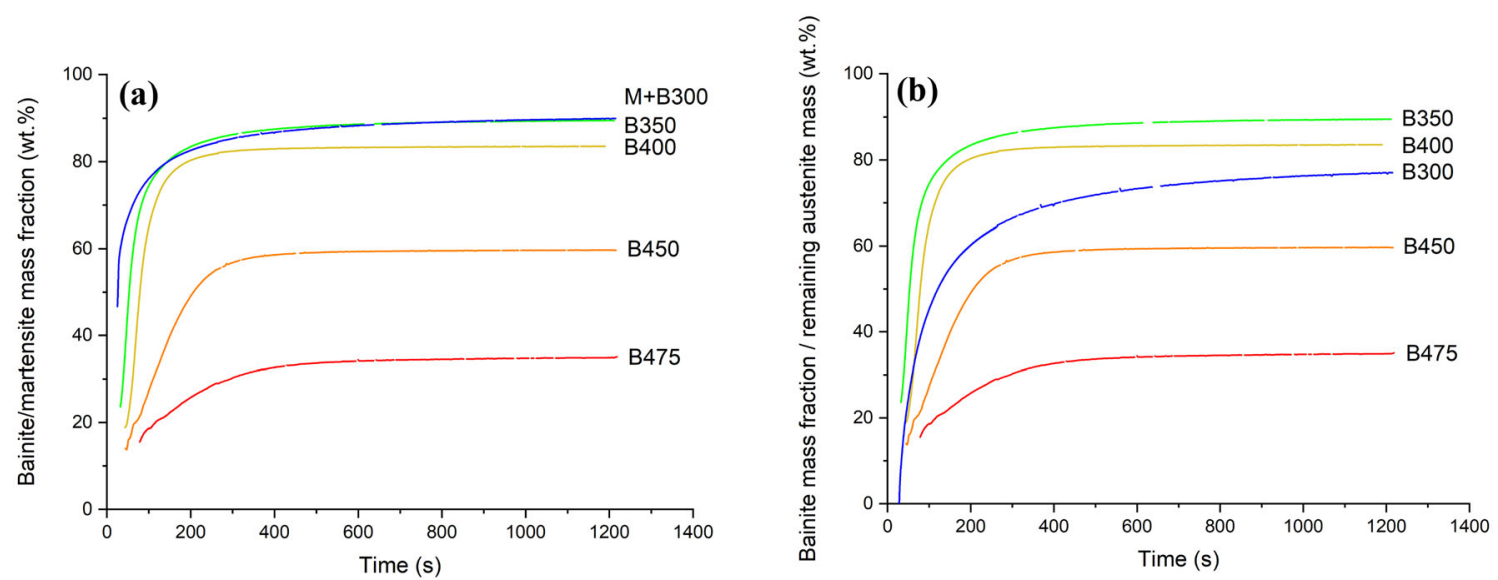

Fig. 3. (a) Bainite and martensite mass fractions as a function of time during isothermal holdings; (b) normalized bainite mass fraction as a function of time in austenite along isothermal holdings (the normalization procedure is explained in the text).

during isothermal holding at different transformation temperatures between $300^{\circ} \mathrm{C}$ and $475^{\circ} \mathrm{C}$ measured by HEXRD. The mass fractions are the direct output of the Rietveld refinement procedure based on the absorption coefficients of atom lattices. The reference time $(t=0)$ was set at the end of the austenitization for all experiments. Bainite mass fractions as a function of time are shown for the 
duration of isothermal holding and do not include potential changes during final cooling to room temperature.

For isothermal holding above $M_{\mathrm{S}}\left(350^{\circ} \mathrm{C}\right.$ and above), the bainite mass fraction increases as a function of time. Bainite formation kinetics exhibit a sigmoidal curve and do not reach a full transformation. The maximum fraction of bainite formed strongly decreases with increasing isothermal temperature: this is consistent with well-established incomplete transformation phenomena in the presence of $\mathrm{Si}$ additions. ${ }^{2,33}$ The higher the temperature, the lower the initial transformation rate and the lower the transformed fraction when the plateau is reached. For the B350 experiment, the slope at the end of the treatment remains significant, meaning that the transformation is not strictly finished (the stasis is probably not reached). ${ }^{9}$

The isothermal transformation at $300^{\circ} \mathrm{C}$ occurs below the $M_{\mathrm{S}}$ temperature. The kinetics of the $\mathrm{M}+$ B300 experiment presented in Fig. 3b are thus the sum of two contributions; first, a martensitic transformation, followed by a bainitic one. In order to compare the bainite transformation rate only in austenite, the kinetics have been normalized to consider only the transformation of the austenite remaining after the martensitic transformation (between $M_{\mathrm{S}}$ and $300^{\circ} \mathrm{C}$, corresponding to a fraction of $F_{\mathrm{M}}=56 \mathrm{wt} . \%$ ). Figure $3 \mathrm{~b}$ shows the normalized kinetics for the different isothermal treatments as a function of time. The normalized bainite mass fraction $F_{\mathrm{B}}$ is calculated as Eq. 1:

$$
F_{\mathrm{B}}=\frac{F_{\mathrm{M}+\mathrm{B}}-F_{\mathrm{M}}}{F_{\mathrm{A}}}
$$

where $F_{\mathrm{M}+\mathrm{B}}, F_{\mathrm{M}}$, and $F_{\mathrm{A}}$ are the total mass fraction of BCT phases (data from Fig. 3), the mass fraction of martensite, and the mass fraction of austenite prior to the bainite transformation, respectively.

When comparing the normalized results, the rate of bainite transformation at $300^{\circ} \mathrm{C}$ is slower than the one obtained at $350^{\circ} \mathrm{C} .{ }^{33,34}$ There is still controversy about the nature of the time dependent transformation observed in such alloys below $M_{\mathrm{S}}$ temperature. ${ }^{34}$ The nature of the final product is claimed to be bainitic or martensitic. Some authors, such as Kim et al. ${ }^{35}$ state that this is an athermal martensitic transformation. However, other authors, such as Van Bohemen et al. ${ }^{36}$ consider the final product to be bainite. In the present article, the isothermal transformation below $M_{\mathrm{S}}$ is also considered to be a bainite transformation.

Nevertheless, this bainitic nucleation is strongly affected by the prior martensitic transformation in the sense that it provides new nucleation sites for bainite, stimulating the autocatalytic nucleation processes at the martensite/austenite interface, as reported, for example, by Ravi et al. ${ }^{37}$ The accelerating effect of a prior martensitic transformation, often observed in the literature, was not found in our experiment of $\mathrm{M}+\mathrm{B} 300 .^{37}$ The bainite fraction reached at the end of the experiment $\mathrm{M}+\mathrm{B} 300$ was 77 wt.\%, lower than the fraction obtained at stasis for B400. For B350, the stasis of the transformation is obviously not achieved as the slope remains significant. Nevertheless, data obtained for isothermal transformation at $300^{\circ} \mathrm{C}(\mathrm{M}+\mathrm{B} 300)$ will be used in later discussion of multi-step experiments.

When cooling the samples down to room temperature, fresh martensite (FM) can be formed if austenite is not sufficiently stabilized by carbon partitioning. Table I shows the final composition of the microstructures. The martensitic transformations during final cooling start at a temperature lower than expected by the local $M_{\mathrm{S}}$ temperature. Moreover, due to the possible distribution of carbon in between austenite islands, it is more difficult to detect correctly the beginning of the transformation, which is more sluggish in this latter case. The $M_{\mathrm{S}}$ calculated using the experimental carbon content determined by HEXRD experiments is reported in Table I. For the sake of comparison, the $\mathrm{M}_{\mathrm{S}}$ temperature calculated and predicted in the last columns of Table I were obtained using the empirical formula from Van Bohemen ${ }^{21}$ and Barbier. ${ }^{22}$ The fraction of FM drastically increases with holding temperature, at the expense of the fraction of austenite reported in Fig. 3b. The highest value of retained austenite fraction at room temperature was obtained after a transformation in B400 under the investigated conditions.

For isothermal transformations at $400^{\circ} \mathrm{C}$ and below, the fresh martensite fraction formed at the end of the thermal treatment was low (close to zero wt.\%). This is consistent with a greater austenite carbon enrichment at these temperatures. For isothermal transformations at $450^{\circ} \mathrm{C}$, a significant fraction of martensite forms during final cooling, consistent with a $M_{\mathrm{S}}$ temperature well above room temperature (lesser austenite carbon enrichment).

For the sake of comparison, the final microstructure after isothermal experiments was examined using scanning electron microscopy after nital (2\%) etching. The microstructures detailed in Table I are shown in Fig. 4. Final microstructures are composed of bainite plates (B), retained austenite (A), and fresh martensite (FM) (the $\mathrm{M}+\mathrm{B} 300$ experiment was not considered in this analysis). The etching is sensitive to the carbon content of the phase. The lower the carbon content, the stronger the response to etching. Bainite thus appears in dark contrast whereas austenite and martensite are hardly etched. Martensite shows a weak roughness and austenite remains completely smooth. At $350^{\circ} \mathrm{C}$, some transition carbides also appear in bright contrast in bainitic laths. These observations are consistent with the HEXRD shown above and discussed later on. 
Table I. Phase fractions at room temperature under isothermal conditions measured by HEXRD and the $M_{\mathrm{S}}$ calculated using Refs. 21 and 22.

\begin{tabular}{|c|c|c|c|c|c|}
\hline $\begin{array}{l}\text { Isothermal } \\
\text { temperature }\left({ }^{\circ} \mathbf{C}\right)\end{array}$ & $\begin{array}{c}\text { Bainite } \\
\text { (wt.\%) }\end{array}$ & $\begin{array}{c}\text { Retained austenite } \\
\text { (wt.\%) }\end{array}$ & $\begin{array}{c}\text { Fresh martensite } \\
(\text { wt. } \%)\end{array}$ & $M_{\mathrm{S}} \underset{\left({ }^{\circ} \mathbf{C}\right)^{21}}{\text { calculed }}$ & $M_{\mathrm{S}}$ calculated \\
\hline 350 & 90 & 10 & 0 & 140 & 136 \\
\hline 400 & 83 & 16 & 1 & 148 & 143 \\
\hline 450 & 60 & 13 & 27 & 257 & 249 \\
\hline 475 & 35 & 7 & 58 & 317 & 306 \\
\hline
\end{tabular}
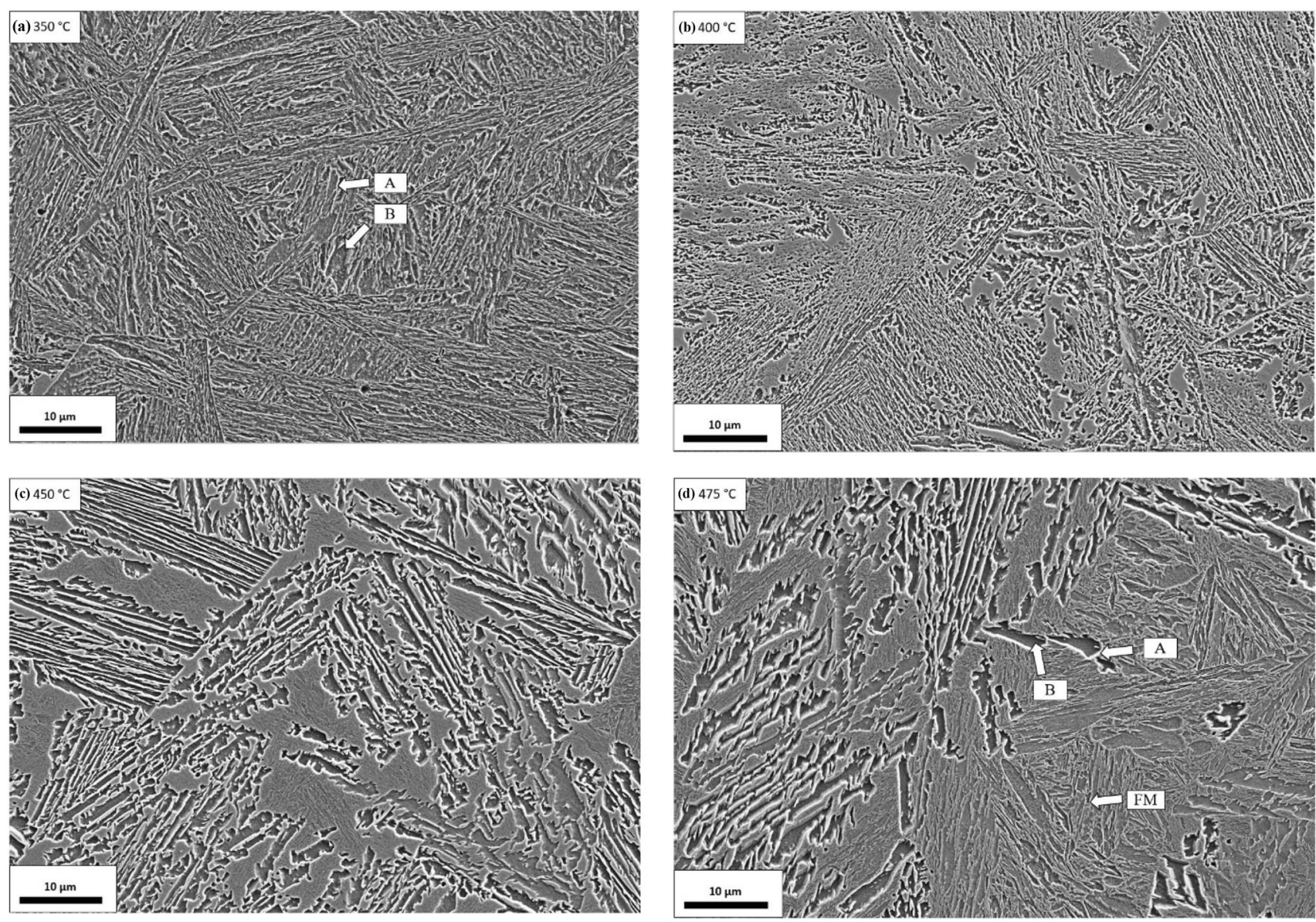

Fig. 4. SEM micrographs after nital (2\%) etching of the studied steel after isothermal experiments at (a) $350^{\circ} \mathrm{C},\left(\right.$ b) $400^{\circ} \mathrm{C},(\mathrm{c}) 450^{\circ} \mathrm{C}$, and (d) $475^{\circ} \mathrm{C}$. When possible, the microstructure components are indicated by white arrows.

\section{Kinetics of Bainite Transformation in Multiphased Microstructures}

Figure 5a, b, and c show the evolution of the BCT phase fraction as a function of time for the three experiments designed to study the bainite transformation below $M_{\mathrm{S}}$, i.e., with varying starting microstructures. The temperature schedules are reported for each experiment. The expected microstructure composition at the transition between isothermal steps is represented schematically to ease the understanding of the transformation sequence. Figure 5a recalls the results previously discussed in Fig. 3a for the sake of comparison.

Figure $5 \mathrm{~b}$ shows the evolution of the bainite mass fraction as a function of time for the $B+M+B 300$ experiment. As for isothermal experiments, the reference time $(t=0)$ is set at the end of the austenitizing. The bainite fraction increases with time all along the two-step cooling and the bainite mass fraction exhibits a sigmoidal curve. During the first step at $400^{\circ} \mathrm{C}$, the bainite mass fraction follows the same evolution as shown previously for an isothermal transformation at the same temperature. At the end of the first step, the mass bainite 

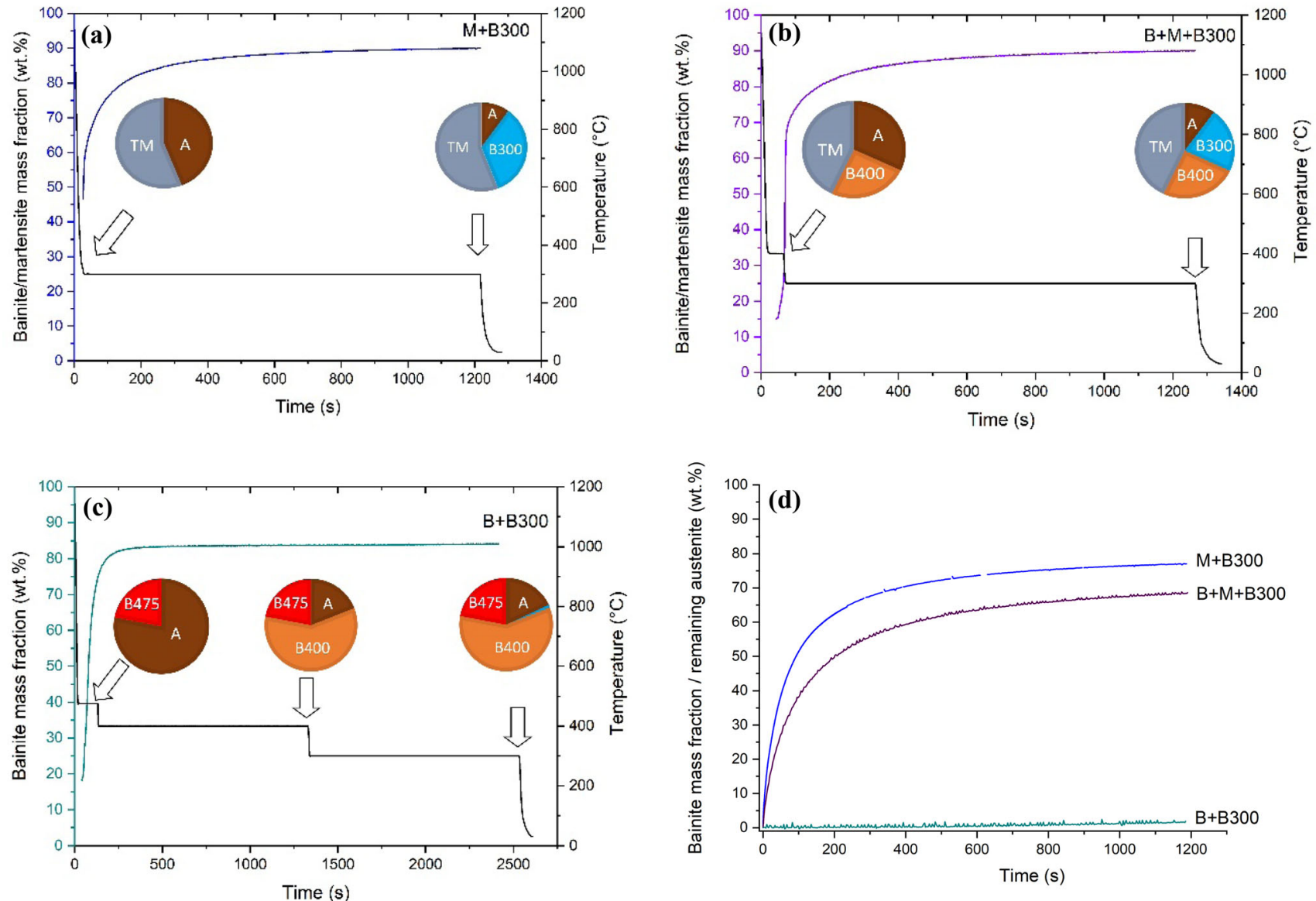

Fig. 5. Time evolutions of temperature and bainite/martensite transformation kinetics. Pie charts illustrate the composition of microstructure at different times. (a) $M+B 300$, (b) $B+M+B 300$, and (c) $B+B 300$ experiments, respectively; (d) normalized bainite kinetics in remaining austenite during the last transformation at $300^{\circ} \mathrm{C}$ for $\mathrm{M}+\mathrm{B} 300, \mathrm{~B}+\mathrm{M}+\mathrm{B} 300$, and $\mathrm{B}+\mathrm{B} 300$ experiments with $44 \mathrm{wt} \%$, 32 wt. $\%$, and 19 wt. $\%$, respectively, of remaining austenite.

Table II. Summary of the microstructure compositions (in wt.\%) before and after the bainitic transformation at $300^{\circ} \mathrm{C}$ (at the end of the step, before final cooling).

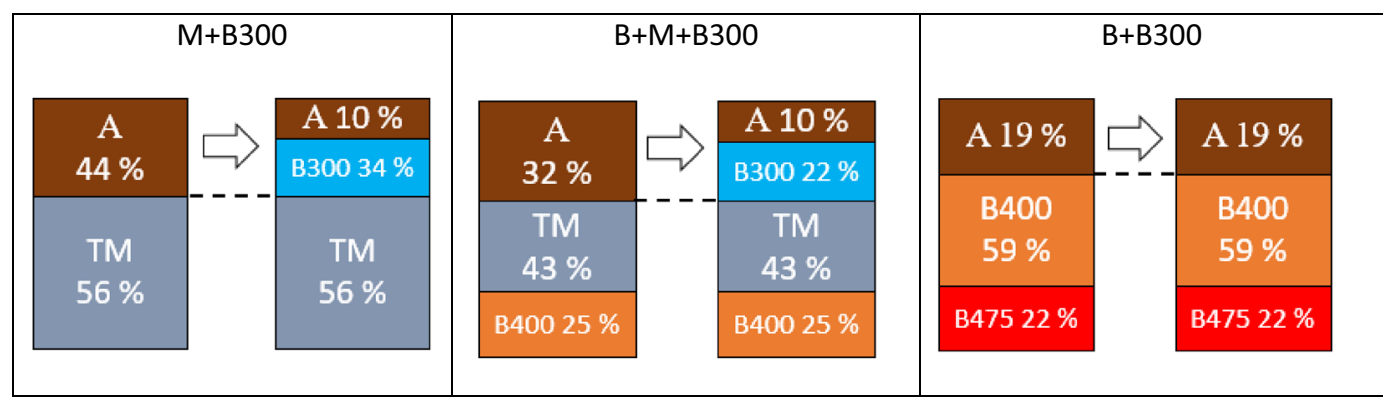

$A$ austenite, $T M$ martensite, $B X X X$ bainite obtained at $\mathrm{XXX}^{\circ} \mathrm{C}$.

fraction is 25 wt.\% and stasis is obviously not reached. During the transition between $400^{\circ} \mathrm{C}$ and $300^{\circ} \mathrm{C}$, a partial martensitic transformation occurs (about $43 \mathrm{wt} . \%$ ). The bainitic transformation restarts during the second step at $300^{\circ} \mathrm{C}$ but with a lower rate than at $400^{\circ} \mathrm{C}$. The fraction transformed at $300^{\circ} \mathrm{C}$ is $22 \mathrm{wt} . \%$. The measured fractions of austenite, martensite, and bainite along the schedule are summarized in Table II. The maximal bainite and martensite mass fraction at the end of the two-step holding is equal to $90 \mathrm{wt} . \%$.

Figure 5c shows the evolution of the bainite mass fraction as a function of time for the three-step treatment B + B300 (green). During the first step at 


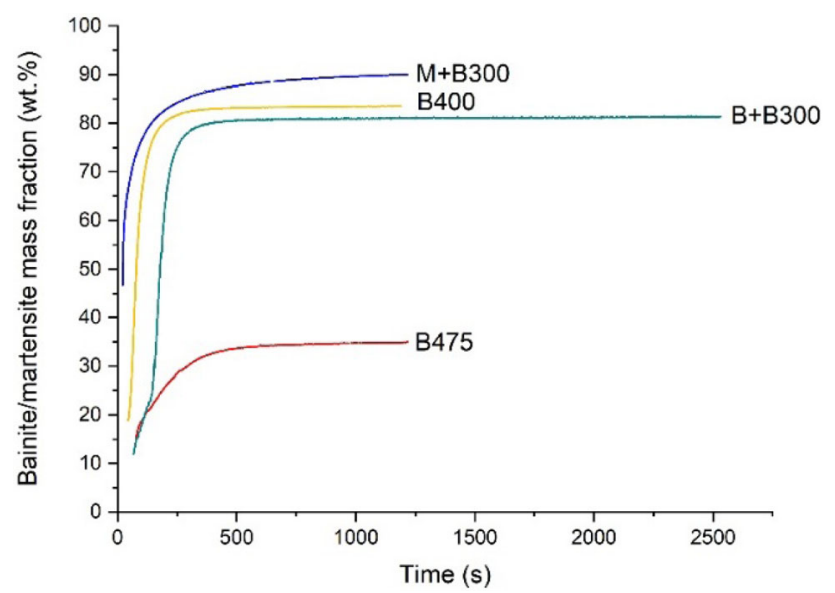

Fig. 6. Kinetics of bainite/martensite transformation during $B+B 300$ experiments respectively (green), isothermal transformations at $475^{\circ} \mathrm{C}$ (red), $400^{\circ} \mathrm{C}$ (yellow), and $300^{\circ} \mathrm{C}$ (blue).

$475^{\circ} \mathrm{C}$, the bainite mass fraction follows the kinetics observed in isothermal transformation as shown in Fig. 6. Figure 6 represents the kinetics of bainite/martensite transformation during the $\mathrm{B}+300$ experiment and isothermal transformations at $475^{\circ} \mathrm{C}, 400^{\circ} \mathrm{C}$, and $300^{\circ} \mathrm{C}$. At the end of this first step, 22 wt. $\%$ of bainite is formed at $475^{\circ} \mathrm{C}$. A change in slope is observed around $120 \mathrm{~s}$; this change in slope is associated with the beginning of the second step. During the second step at $400^{\circ} \mathrm{C}$, the transformation thus continues. The kinetics are slower than the ones observed during the B400 experiment alone for the corresponding fraction of bainitic ferrite formed. However, the bainite mass fraction reached at stasis during isothermal transformation of B400 is slightly higher (around 85 wt.\%) than the maximal value of bainite mass fraction at stasis after a multi-step heat treatment of B + B300 (around 80 wt.\%). These experiments highlight that a bainite transformation can restart at a lower temperature if the bainite fraction is not large enough. The bainite transformation thus does not respect the additivity rule as observed by Hasan et $\mathrm{al}^{38}$

The estimated fraction main phases (austenite and bainite) formed during the first step at $400^{\circ} \mathrm{C}$ and bainite formed during the second step are presented in Table II.

Figure 5d shows the normalized bainite kinetics in the remaining austenite during $\mathrm{M}+\mathrm{B} 300$ isothermal holding (blue) and during the last step at $300^{\circ} \mathrm{C}$ for the $\mathrm{B}+\mathrm{M}+\mathrm{B} 300$ (purple) and B + B300 (green) conditions, respectively (see Fig. 1). The reference time $(t=0)$ is fixed here at the beginning of the $300^{\circ} \mathrm{C}$ holding for the sake of comparison. The bainite kinetics show sigmoidal (or saturating exponential) shapes with different saturation levels. In all cases, however, the bainite mass fractions do not reach a plateau, meaning that the transformation is not finished.
In isothermal conditions at $\mathrm{M}+\mathrm{B} 300$ (after 56 wt.\% of martensitic transformation), the transformation rate is higher than the kinetics during holding at $300^{\circ} \mathrm{C}$ under the $\mathrm{B}+\mathrm{M}+\mathrm{B} 300$ condition (after 68 wt.\% of B/M transformation). The fraction of bainite at $300^{\circ} \mathrm{C}$ at the end of the steps is also very different (34 wt.\% and 22 wt.\%, respectively). These results are surprising as the fractions of austenite at the beginning of the transformation are similar (44 wt.\% and 32 wt.\%, respectively) as well as their local carbon content. For the $300^{\circ} \mathrm{C}$ bainite transformation during the last step of the B+B300 cooling sequence, less than 1 wt.\% of bainite formed, meaning that the transformation at $300^{\circ} \mathrm{C}$ is completely inhibited in that case, allowing a higher fraction of retained austenite at the end of the step (19 wt.\% instead of $10 \mathrm{wt} . \%$ ). The conditions of stasis are thus very different compared with the two previous cases. Moreover, this highlights that bainite transformations do not respect the additivity rule.

\section{Evolution of Tetragonality}

The $c$ and a lattice parameters of the BCT phase were obtained from the Rietveld refinement of insitu acquired data. This measurement is not affected by the possible mechanisms disturbing the widths of the diffraction peaks as the tetragonality is observed solely on certain diffraction peaks.

Figure 7a shows the evolution of the c/a ratio as a function of time during isothermal holding at temperatures between $350^{\circ} \mathrm{C}$ and $475^{\circ} \mathrm{C}$. The other experiments have been excluded as it is not possible to convincingly isolate the behavior of bainite and martensite if present at the same time in the microstructure.

The changes in c/a ratio evolutions may be divided into two parts: at the beginning of the bainite transformation, the c/a ratio increases rapidly during the first $100 \mathrm{~s}$. During the second stage, it decreases continuously while remaining above 1 (value corresponding to an ideal body-centered cubic structure). The lower the holding temperature, the higher the c/a ratio.

\section{Evolution of Austenite Lattice Parameter}

Figure $7 \mathrm{~b}$ represents the austenite lattice parameters measured by HEXRD as a function of time along isothermal holdings at temperatures between $350^{\circ} \mathrm{C}$ and $475^{\circ} \mathrm{C}$. The initial values differ as the lattice parameter of stress-free austenite increases with temperature due to thermal expansion. At the onset of isothermal holding, the austenite is assumed to represent the nominal composition.

For all studied isothermal holdings, the evolution of austenite lattice parameters shows a sigmoidal shape. Hence, for all temperatures, an enrichment in carbon in austenite is observed during bainite formation if we neglect the transformation stresses. 

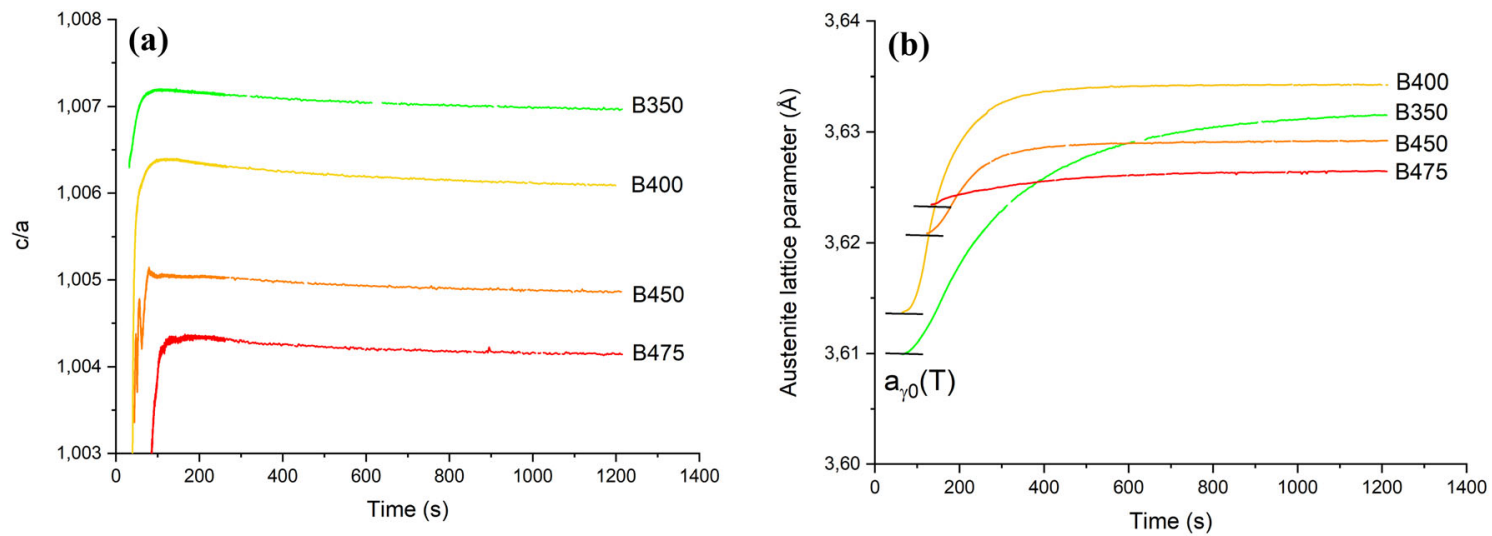

Fig. 7. (a) Evolution of $c / a$ ratio of BCT phase under isothermal conditions; (b) evolution of the austenite lattice parameter under isothermal conditions with the $a_{\gamma 0}(T)$ set at the minimum austenite lattice parameter at a given temperature.

At low temperature $\left(350^{\circ} \mathrm{C}\right)$, the austenite lattice parameter does not show any saturation regime at the end of the experiment (after $20 \mathrm{~min}$ ). This is consistent with the transformation kinetics observed at the same temperature. The transformation still continues during the whole experiment without reaching a real stasis.

In contrast, for B400, B450, and B475 experiments, a stasis is observed. The higher the transformation temperature, the lower the increase in the austenite lattice parameter at the end of the holding. The carbon enrichment of austenite at stasis decreases as the temperature increases. A quantification of the carbon enrichment, thanks to the Dyson and Holmes equation, ${ }^{39}$ will be discussed in the next section.

The evolution of austenite lattice parameters for transformations below $M_{\mathrm{S}}$ are analyzed and discussed in the Supplementary Materials (Fig. S1).

\section{DISCUSSION}

\section{Transformations Above $\mathbf{M}_{\mathbf{S}}$}

In this section, only the experiments B350 to B475 will be discussed as the microstructures along the studied isothermal holdings contain only two phases, i.e., bainite and austenite (before the final cooling during which a martensitic transformation can occur). Thanks to the measurement of the austenitic lattice parameter and the bainite tetragonality, it is possible to establish a rigorous carbon mass balance between the phases, all along the treatments. This mass balance helps to characterize, in particular, the local composition of the phases at the end of the treatment, when the transformations reach their stasis (or almost stasis as is the case at $350^{\circ} \mathrm{C}$ ). The compositions in both phases are then discussed in light of the different theories about bainitic transformations. Finally, it will be shown that the balances also provide evidence that a minor fraction of carbides also precipitates during the transformation at lower temperature. This precipitation is confirmed by a careful direct observation of the diffraction patterns and of final microstructures after etching.

For the other experiments $(\mathrm{M}+\mathrm{B} 300, \mathrm{~B}+\mathrm{M}+$ B300, B + B300) multiple phases are formed which jeopardizes the establishment of this balance in a reliable way.

\section{Evolution of the Carbon Content in the Constituting Phases (Bainite and Austenite)}

The austenite lattice parameter can be tracked all along the treatment, as shown in Fig. 7b. Assuming the variation of the parameter is solely due to the carbon enrichment of austenite due to the carbidefree bainitic reaction, and thus neglecting any evolution in the hydrostatic internal stress of the phase due to displacive transformation, the carbon content in the retained austenite can be calculated using the equation from Dyson and Holmes: ${ }^{39}$

$$
C_{\mathrm{A}}=C_{0}+\frac{a_{\gamma}-a_{\gamma 0}(T)}{0.033}
$$

where $C_{\mathrm{A}}$ and $C_{0}$ are the carbon content in the retained austenite and the initial carbon content of the phase before transformation $(0.27 \mathrm{wt} . \%)$ given in wt.\%; $a_{\gamma}$ and $a_{\gamma 0}(T)$ are the austenite lattice parameters of the carbon-enriched retained austenite and the austenite lattice parameter reference before bainite transformation starts, respectively, given in $\AA$. This last parameter depends on the transformation temperature as shown in Fig. 7b. This procedure to evaluate the local composition in austenite is very common and has been exploited extensively in previous papers. ${ }^{2,40,41}$ It is well established that carbon is not homogeneously distributed throughout the austenite. The films of retained austenite are often more enriched than blocky austenite. The carbon content measured by HEXRD appears to be a mean value. This has been clearly demonstrated by Pushkareva et al. on two very similar alloys and transformation conditions. The final austenite carbon content measured by HEXRD has been compared with ${ }^{42}$ direct 
measurements of the carbon content in austenite by EELS (electron energy loss spectroscopy). In nanobainitic steels, Garcia-Mateo et al. ${ }^{41}$ observed a strong dispersion in carbon content values using APT (atom probe tomography). The austenite carbon content measured by HEXRD is a mean value taking into account the film-like carbon-rich austenite and the carbon-poor blocky austenite, and is closer to these last values. As done by some authors, ${ }^{2,43}$ the heterogeneity of carbon content can be estimated taking into consideration two austenite phases in the Rietveld refinement procedure.

The fact the HEXRD leads to mean carbon content measurements close to the ones that could be given by EELS or by APT sustains the hypothesis that the hydrostatic stresses do not play a major role in the evolution of the lattice parameter of austenite during the bainitic transformation and do not in turn affect the measurement of carbon content. It must be mentioned that this is not the case if the bainitic transformation is preceded by a martensitic transformation, as is the case for $\mathrm{Q} \& \mathrm{P}$ steels. ${ }^{44,45}$

Figure 8 shows the evolution of the carbon content in austenite determined according to the procedure described above. As expected, the carbon content increases in all cases following sigmodal curves, i.e., with a rapid initial enrichment starting from the nominal carbon content $(0.27 \mathrm{wt} . \%)$ then followed by a plateau. It must be emphasized that the plateau/stasis was not reached in the B350 experiment. For the experiments that did reach the plateau, the carbon content in austenite at the plateau decreased with temperature. This trend is consistent with the fraction of retained austenite at stasis assuming a first-order carbon balance.

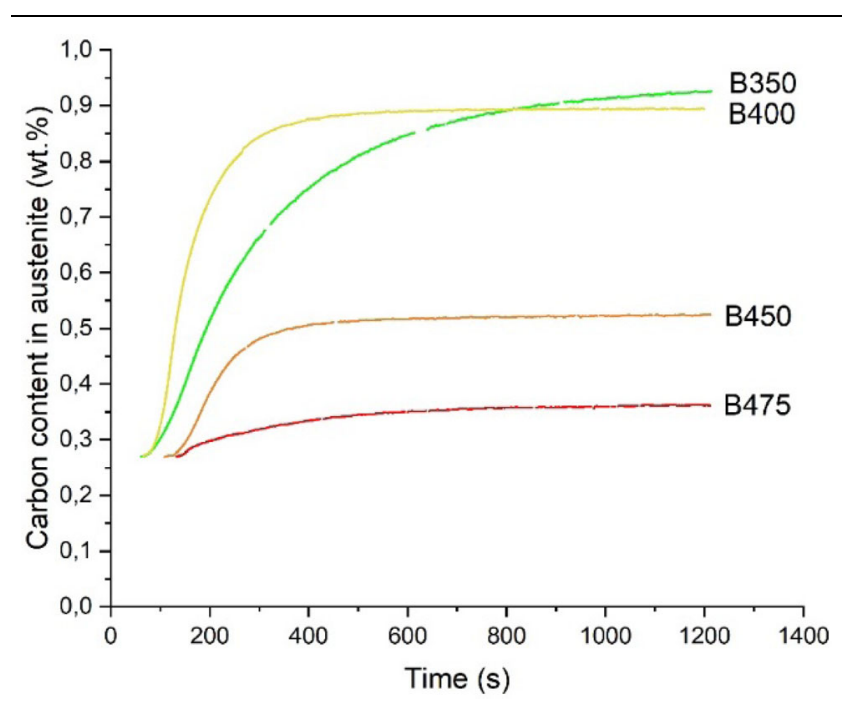

Fig. 8. Carbon content in retained austenite as a function of time during the isothermal holdings between $350^{\circ} \mathrm{C}$ and $450^{\circ} \mathrm{C}$, determined by the procedure detailed in the text (nominal carbon content 0.27 wt. \%).

$$
C_{\mathrm{A}}=\frac{C_{0}}{F_{\mathrm{A}}}
$$

The higher the fraction of retained austenite, the lower the enrichment is. This last equation supposes a complete partition of carbon between bainite and austenite. However, this too simple equation cannot hold. For B400 at stasis, the fraction of retained austenite is $17 \mathrm{wt} . \%$ meaning that the expected carbon content should be $1.76 \mathrm{wt} \%$ instead of $0.89 \mathrm{wt} \%$. It thus means that a significant fraction of carbon remains in fact trapped in bainitic ferrite, which, in turn, explains the tetragonality of the ferritic lattice shown in Fig. 7a.

According to the Zener ordering theory, ${ }^{46}$ the carbon atoms in solid solution in a ferritic lattice tend to segregate collectively to certain octahedral sites of the BCC lattice and distort it. It is commonly admitted that a BCT structure is then obtained. The distortion of the lattice was shown to be proportional to the carbon content in solid solution. As in previous published works on bainitic and martensitic steels, the carbon content in bainite can be estimated on the basis of the tetragonality as follows: ${ }^{2,47-50}$

$$
\frac{c}{a}=1+0.045 C_{\mathrm{B}}
$$

where $C_{\mathrm{B}}$ is the concentration of carbon in wt.\%.

In the literature, it is not clear whether this estimation of the carbon content also encompasses carbon clusters or carbon segregated at defects, such as dislocations or bainitic lath boundaries. ${ }^{19,51}$ Moreover, it must be mentioned that the recent works of Maugis et al. show that the distortion due to Zener's ordering could also lead to an orthorhombic lattice under a compressive stress state (tetragonal in tension). ${ }^{52,53}$ This could explain why an even better agreement can be obtained with an orthorhombic lattice to model the diffraction peaks. $^{28}$

As a consequence, the estimated carbon content in bainite follows the trends illustrated in Fig. 7a if Eq. 4 applies. For the four isothermal experiments above $M_{S}$, the carbon content first increases rapidly and then decreases smoothly after about $100 \mathrm{~s}$. It is not possible to give a physical meaning to the initial rapid increase as the fraction of bainite being low and as a consequence, the uncertainty related the tetragonality measurement is too high. However, the trends after $100 \mathrm{~s}$ are more relevant. The lower the transformation temperature is, the higher the carbon content in bainite (from 0.09 wt. $\%$ at $450^{\circ} \mathrm{C}$ up to 0.15 wt. $\%$ at $350^{\circ} \mathrm{C}$ at the end of the experiments). These high values are consistent with the values reported in the literature in similar alloys and have been used to support the diffusionless theory $^{28,30}$ of bainitic transformation. At the beginning of transformation, supersaturated bainite nucleates with a carbon content equal to the prior 
Table III. Phase fractions and carbon contents measured by HEXRD at the end of holdings; the estimated $\Delta C$ by a simple carbon mass balance.

\begin{tabular}{|c|c|c|c|c|c|}
\hline $\begin{array}{l}\text { Isothermal } \\
\text { temperature } \\
\left({ }^{\circ} \mathrm{C}\right)\end{array}$ & $\begin{array}{c}\text { Bainite mass } \\
\text { fraction }(w t . \%) F_{B}\end{array}$ & $\begin{array}{c}\text { Bainite carbon } \\
\text { content }(w t . \%) C_{B}\end{array}$ & $\begin{array}{c}\text { Austenite mass } \\
\text { fraction }(w t . \%) F_{A}\end{array}$ & $\begin{array}{l}\text { Austenite carbon } \\
\text { content }(w t . \%) C_{A}\end{array}$ & $\Delta C$ \\
\hline 350 & 90 & 0.15 & 10 & 0.92 & 0.03 \\
\hline 400 & 84 & 0.14 & 16 & 0.89 & 0.01 \\
\hline 450 & 60 & 0.11 & 40 & 0.52 & 0.00 \\
\hline 475 & 35 & 0.09 & 65 & 0.36 & 0.00 \\
\hline
\end{tabular}

austenite. During the transformation process, the $c / a$ ratio decreases by partitioning.

\section{Carbon Mass Balance at the End of the Isothermal Holding}

Table III summarizes the phase fractions and carbon contents at the end of isothermal experiments at temperatures above $\mathrm{M}_{\mathrm{S}}$. The isothermal transformation at $300^{\circ} \mathrm{C}(\mathrm{M}+\mathrm{B} 300)$ has been discarded as it is difficult to deconvolute correctly the effect of prior martensite transformation on the carbon content in bainite. Moreover, for this particular experiment, the transformation is far from having reached a stasis. The first column contains the temperature of isothermal holding. The second and the fourth columns contain the bainite mass fraction $F_{B}$ (wt.\%) and the austenite mass fraction $F_{A}$ (wt.\%), respectively, determined by Rietveld refinement. The third column shows the $C_{B}$ in wt.\% corresponding to the carbon content in bainite obtained thanks to the tetragonality factor c/a at the end of the isothermal holding using Eq. 4.

The last column contains the carbon deficit, $\Delta C$, calculated as:

$$
C_{0}=C_{\mathrm{B}} F_{\mathrm{B}}+C_{\mathrm{A}} F_{\mathrm{A}}+\Delta C
$$

where $C_{0}$ is the nominal carbon content in the steel grade. The function $\Delta \mathrm{C}$ represents the carbon not found in austenite or in bainite by the independent determination of the carbon trapped in each phase. $\Delta C$ is thus thought to represent the carbon trapped in carbides.

The mathematical error in the Rietveld procedure for the determination of the phase fractions is $\pm 1 \mathrm{wt} . \%$. In contrast, the relative error on the measurement of the austenite lattice parameter is low $\left(2.10^{-4}\right)$. The errors made on the tetragonality are more difficult to evaluate as it could depend on the way in which the width of diffraction peaks is modeled. Moreover, the determination of $C_{\mathrm{B}}$ using the tetragonality of the BCT lattice can be discussed. $^{48}$ Nevertheless, the high degree of confidence on the phase fraction and lattice parameter of austenite leads to the same conclusion that a significant part of the carbon content remains in fact trapped in bainite. The order of magnitude of the carbon content out of austenite $\left(C_{\mathrm{B}} F_{\mathrm{B}}+\Delta C\right)$

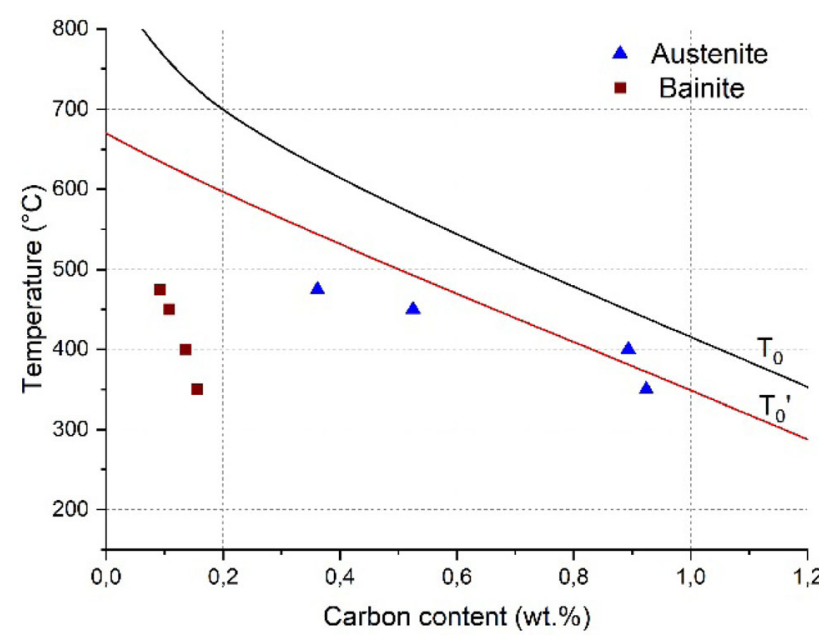

Fig. 9. Carbon content in retained austenite (triangles) and in bainite (squares) for isothermal conditions ( $T_{0}$ and $T_{0}^{\prime}$ lines).

would have given similar $C_{\mathrm{B}}$ values between 0.2 wt. $\%$ and 0.1 wt. $\%$. These values are indubitably higher than the values expected in a BCC phase after a transformation under paraequilibrium.

In the following, the values presented in Table III (carbon composition of austenite and bainite at the end of the experiments) will be discussed in light of the diffusionless theory for carbide-free bainitic transformation. Finally, the very low residual fraction of carbon $\Delta C$ will be shown to be explained by the presence of carbides (precipitated carbon). In the Rietveld refinement procedure, only austenite and bainite are considered. Nevertheless, the fraction of precipitates remains very low (far below the experimental resolution) and doesn't affect the fraction measured above.

\section{Carbon in Austenite and Validity of $T_{o}^{\prime}$ Criterion}

The carbon contents in retained austenite at the end of the studied isothermal holdings are shown in Fig. 9. These values are compared with the $T_{0}$ and $T_{0}^{\prime}$ lines calculated with Thermocalc software and the TCFE9 database. These lines represent the supposed thermodynamic limits for bainite nucleation assuming the equality of the Gibbs energy of BCC ferrite (representing bainite) and austenite. The $T_{0}{ }^{\prime}$ line also takes into account an additional 
elastic strain energy of $400 \mathrm{~J} \cdot \mathrm{mol}^{-1}$ in the ferrite in accordance with the diffusionless theory of Bhadeshia. $^{13}$

Experimental austenite carbon contents are close to the $T_{0}^{\prime}$ line only at the lower transformation temperatures (B400 and B350 experiments). For the latter, the transformation was shown to not have reached stasis (transformation time is too short). The value presented here is thus low compared with the value really expected at stasis. In contrast, at high temperatures (B450 and B475 experiments) the values are far from the $T_{0}{ }^{\prime}$ line even if the kinetics show a clear stasis in the transformation (cf. Fig. 3a). Such discrepancy between experiment and $T_{0}^{\prime}$ line at high temperatures has also been reported by some groups. ${ }^{2,8,54}$ The $T_{0}{ }^{\prime}$ criterion seems thus to be validated at low temperature but is clearly not verified at high temperatures.

\section{Carbon Supersaturation in Bainite}

The carbon content in bainite obtained at the end of our isothermal experiments is represented by red squares (values found in Table III) in Fig. 9.

The recent criterion assuming the equality of the Gibbs energy of a BCT phase (representing bainite more convincingly) and austenite proposed by Ranjan et al. ${ }^{54}$ could explain why the carbon content in austenite could exceed the conventional $T_{0}{ }^{\prime}$ line at the lower temperatures: at high temperatures, the new criterion cannot explain why the stasis is reached sooner than expected from the criterion.

For the sake of comparison, the values obtained on similar alloys after isothermal holdings by Pushkareva et al., ${ }^{42}$ Garcia-Mateo et al., ${ }^{29}$ and by Ranjan et al. ${ }^{54}$ have been compared with our values. Pushkareva et al. ${ }^{42}$ measured the carbon content in bainitic laths by EELS (electron energy loss spectroscopy) whereas Garcia-Mateo et al. ${ }^{29}$ and Ranjan et al. ${ }^{54}$ used APT (atom probe tomography).

The lower the temperature, the higher the carbon content in bainite is. These results are in agreement with results from the literature. ${ }^{29,32,42,54,55}$ Ranjan et al. ${ }^{54}$ have recently explained this evolution by a correlation with the austenite carbon content, which also increases.

As already discussed, these values are high compared with the carbon solubility in BCC phase and supports, according to, ${ }^{54}$ the diffusionless theory of bainitic transformation. The results for all the isothermal experiments plead in favor of a bainite formed at low temperature following the lower bainite description of Bhadeshia. ${ }^{13}$ Carbon remains trapped in bainite at low temperature since the diffusion of carbon is slow at low temperature. CFB obtained under isothermal conditions is thus highly supersaturated in carbon and its carbon content depends on the transformation temperature.

\section{Carbides}

The $\Delta \mathrm{C}$ values identified in Table III represent the carbon missing in solid solution in bainite and in austenite. The values found are weak (max. $10 \mathrm{wt} . \%$ of the nominal carbon content) and decrease with increasing transformation temperatures. Above $400^{\circ} \mathrm{C}$, the values are negligible considering the precision of the measurement.

If solid solution is set aside, the other possible mechanisms able to trap carbon are numerous: segregation on dislocations, segregation on lath/ block/packet boundaries, local enrichment in austenite, or precipitation of carbides. In the literature, it is not well established whether the carbon segregates on defects also contribute to the obvious tetragonality observed in the bainitic phase. ${ }^{19,56}$

The presence of carbides is a better explanation of the $\Delta C$ values at low transformation temperatures (mainly at $350^{\circ} \mathrm{C}$ ). In fact, carbides can also be directly evidenced by SEM observations and by looking carefully at diffractograms, as shown in Fig. S2, Supplementary Materials. At $350^{\circ} \mathrm{C}$, the transition carbides mass fraction is estimated to be less than 1 wt.\% using a manual refinement value (the uncertainty in phase fraction obtained by the Rietveld refinement is \pm 1 wt.\%) that is consistent with the one obtained by the carbon mass balance. As a consequence, it is not possible to decide whether the whole $\Delta \mathrm{C}$ value can be explained by these carbides.

It must be mentioned that the steel contains around 0.1 wt. $\%$ of sulfur. As a consequence, it contains a large fraction of $\mathrm{MnS}$ which is well highlighted on the diffractograms in Fig. S2, Supplementary Materials (cyan boxes). Even if the studied steel presents a large fraction of $\mathrm{MnS}$, the mean Mn composition in the matrix is not affected (no effect on $M_{\mathrm{s}}$ and $T_{0}$ lines). On the diffraction patterns, there are no overlapping peaks between $\mathrm{MnS}$, transition carbides, and cementite.

\section{Transformation Below $\mathbf{M}_{\mathbf{S}}$}

In this section, we discuss the outcomes of the "step treatments", which include as a last step an isothermal treatment at $300^{\circ} \mathrm{C}$, below the $M_{\mathrm{S}}$, during which a bainite transformation will take place.

We compare the kinetics of the bainite transformation as a function of starting microstructure, as recalled in Table II. As shown in Fig. 5, the bainite transformation kinetics at $300^{\circ} \mathrm{C}$ are drastically different among the three experiments, despite a significant amount of austenite remaining to be transformed in all cases.

These differences in kinetics can be interpreted qualitatively. The kinetics of $\mathrm{M}+\mathrm{B} 300$ are fastest because the initial austenite fraction is the highest 
Table IV. Austenite mass fractions and carbon contents measured by HEXRD at the end of the last step of multi-step cooling sequences.

\begin{tabular}{|c|c|c|c|}
\hline Cooling sequence & Temperature $\left({ }^{\circ} \mathbf{C}\right)$ & Austenite mass fraction $(\%)$ & Austenite carbon content (wt.\%) \\
\hline $\mathrm{B}+\mathrm{M}+\mathrm{B} 300$ & 300 & 10 & 0.91 \\
\hline $\mathrm{B}+\mathrm{B} 300$ & 300 & 19 & 0.93 \\
\hline
\end{tabular}

and because the austenite did not have time to get enriched in carbon during the martensitic transformation down to $300^{\circ} \mathrm{C}$. According to previous works, ${ }^{33,37}$ the new martensite/austenite interfaces also provide nucleation sites, which accelerate the bainite transformation.

For the experiment B + B300, the kinetics are the slowest (almost no detectable bainite transformation) because it has the lowest amount of austenite in the initial microstructure and the austenite was enriched by carbon (0.93 wt.\%). The kinetics of the $\mathrm{B}+\mathrm{M}+\mathrm{B} 300$ experiment are intermediate because there is more austenite remaining than in the latter experiment, it is less enriched with carbon (0.91 wt.\%), and the martensite provides new nucleation sites.

Accordingly, the austenite fraction at the end of the bainite transformation at $300^{\circ} \mathrm{C}$ is the highest for the B + B300 treatment. Let us mention that the final carbon concentration is quasi similar among the two experiments (Table IV), showing that the final stasis is not simply related to this parameter. The previously formed microstructure modifies the carbon mass balance and therefore the final fraction of austenite.

Hence, these experiments show that the overall bainite transformation is not simply linked with the temperature and the fraction of already-formed bainite (i.e., it is not additive): it depends on the already formed microstructure, which is itself dependent on the previous thermal history. This conclusion is in agreement with previous investigations by Hasan et al. ${ }^{38}$ The non-additivity was highlighted above the $M_{\mathrm{S}}$ temperature in Fig. 6. Put together, these results are in agreement with previous studies which recently demonstrated that multi-step cooling sequences are more efficient for stabilizing retained austenite at room temperature than conventional single isothermal treatments. ${ }^{38,57,58}$ This is of both practical and industrial interest, ${ }^{1,4}$ even if its origin remains poorly understood.

Table IV is a summary of austenite fractions and austenite carbon contents at the end of the last step at $300^{\circ} \mathrm{C}$ for the $\mathrm{B}+\mathrm{M}+\mathrm{B} 300$ and $\mathrm{B}+\mathrm{B} 300$ cooling sequence. As shown above, the final fraction of austenite at the end of the treatment depends on the whole thermal sequence. A higher fraction of retained austenite is measured at the end of the B + B300 treatment, even if the austenite carbon content at the end of the final step is very close for both multi-step treatments. Hence, the retained austenite fraction and carbon composition depend on the transformation history. Both are key for understanding the mechanical performance of these microstructures and sustaining their industrial interest. $^{1,4}$

\section{CONCLUSION}

Bainite transformations were investigated by insitu high-energy X-ray diffraction above and below the $M_{\mathrm{S}}$ temperature. These experiments have permitted the determination of bainite kinetics of transformation along isothermal and multi-step cooling sequences with good accuracy. The composition of phases was tracked using the determination of the austenite lattice parameter and the tetragonality of the bainite lattice. At the end of isothermal holdings, a carbon enrichment was observed in austenite, despite the high carbon content trapped in bainite (in particular for low temperature conditions). The austenite carbon content at the end of the holding was compared with the displacive criterion $T_{0}{ }^{\prime}$ line. The experimental values are close to the $T_{0}^{\prime}$ line; however, this criterion is not respected for high temperature transformation. For transformations above $M_{\mathrm{S}}$, a precise carbon mass balance is proposed, highlighting carbide formation at the lowest temperature. For transformations below $M_{\mathrm{S}}$, the bainite transformation is dependent on the history and previous transformations. This sensitivity has been explained in terms of austenite stability and nucleation processes. The bainite transformation thus does not respect the additivity rule.

\section{ACKNOWLEDGEMENTS}

This work was supported by Ascometal (CREAS) Hagondange. The synchrotron experiments were realized in 2018 under Project I-20180850 EC at DESY PETRA III in Hamburg. The authors would like to thank the team of P07 line, in particular Norbert Schell and Andreas Stark. Their expertise was very much appreciated and widely contributed to the success of the study.

\section{FUNDING}

This work was funded by Ascometal, Swiss Steel group, by the Universite de Lorraine, by the CNRS (Centre de la Recherche Scientifique) and the French ANRT (Agence National de la Recherche et de la Technologie) under the CIFRE convention (2018/1307). The HEXRD experiments were con- 
ducted at DESY (PETRA III-P07 beamline) in Hamburg.

\section{CONFLICT OF INTEREST}

The authors declare that they have no conflicts of interest.

\section{SUPPLEMENTARY INFORMATION}

The online version contains supplementary material available at https://doi.org/10.1007/s11837021-04903-8.

\section{REFERENCES}

1. F.G. Caballero, S. Allain, J. Cornide, J.D. Puerta Velásquez, C. Garcia-Mateo, and M.K. Miller, Mater. Des. 49, 667. (2013).

2. L. Guo, H.K.D.H. Bhadeshia, H. Roelofs, and M.I. Lembke, Mater. Sci. Technol. 33, 2147. (2017).

3. H.I. Aaronson, W.T. Reynolds, and G.R. Purdy, Metall. Mater. Trans. A 37, 1731. (2006).

4. T. Sourmail, J. Heat Treat. Mater. 72, 371. (2017).

5. T. Sourmail, C. Garcia-Mateo, F. Caballero, L. Morales-Rivas, R. Rementeria, and M. Kuntz, Metals 7, 31. (2017).

6. B.C. De Cooman, Curr. Opin. Solid State Mater. Sci. 8, 285. (2004).

7. W.T. Reynolds, F.Z. Li, C.K. Shui, and H.I. Aaronson, Metall. Trans. A 21, 1433. (1990).

8. H.-D. Wu, G. Miyamoto, Z.-G. Yang, C. Zhang, H. Chen, and T. Furuhara, Acta Mater. 133, 1. (2017).

9. M.A. Santajuana, A. Eres-Castellanos, V. Ruiz-Jimenez, S. Allain, G. Geandier, F.G. Caballero, and C. Garcia-Mateo, Metals 9, 925. (2019).

10. M.Y. Sherif, C.G. Mateo, T. Sourmail, and H.K.D.H. Bhadeshia, Mater. Sci. Technol. 20, 319. (2004).

11. J.-C. Hell, M. Dehmas, S. Allain, J.M. Prado, A. Hazotte, and J.-P. Chateau, ISIJ Int. 51, 1724. (2011).

12. F.G. Caballero, and H.K.D.H. Bhadeshia, Curr. Opin. Solid State Mater. Sci. 8, 251. (2004).

13. H.K.D.H. Bhadeshia, Bainite in Steels: Transformations, Microstructure and Properties, 2nd edn. (IOM Communications, London, 2001).

14. Z. Tournoud, Caractérisation Multi-Échelle d'un Acier Bainitique Microallié à Effet TRIP, PhD Thesis, Université Grenoble Alpes (ComUE), 2019.

15. L.C.D. Fielding, Mater. Sci. Technol. 29, 383. (2013).

16. A.M. Ravi, J. Sietsma, and M.J. Santofimia, Acta Mater. 105, 155. (2016).

17. D. Quidort, and Y.J.M. Brechet, Acta Mater. 49, 4161. (2001).

18. S. Allain, S. Aoued, A. Quintin-Poulon, M. Gouné, F. Danoix, J.-C. Hell, M. Bouzat, M. Soler, and G. Geandier, Materials 11, 1087. (2018)

19. R. Rementeria, J.A. Jimenez, S.Y.P. Allain, G. Geandier, J.D. Poplawsky, W. Guo, E. Urones-Garrote, C. GarciaMateo, and F.G. Caballero, Acta Mater. 133, 333. (2017).

20. https://www.ascometal.com/.

21. S.M.C. van Bohemen, Mater. Sci. Technol. 28, 487. (2012).

22. D. Barbier, Adv. Eng. Mater. 16, 122. (2014).

23. D. Forgeoux, Application Des Structures Bainitiques Par Transformation Isotherme et d'un Traitement de Surface Adapté Aux Vis à Haute Résistance, Thesis, Université de Technologie de Belfort-Montbeliard, 2016.
24. G. Ashiotis, A. Deschildre, Z. Nawaz, J.P. Wright, D. Karkoulis, F.E. Picca, and J. Kieffer, J. Appl. Crystallogr. 48, 510. (2015).

25. H.M. Rietveld, J. Appl. Crystallogr. 2, 65. (1969).

26. J. Rodríguez-Carvajal, Phys. B Condens. Matter 192, 55 (1993).

27. B.H. Toby, Powder Diffr. 21, 67. (2006).

28. C.N. Hulme-Smith, I. Lonardelli, A.C. Dippel, and H.K.D.H. Bhadeshia, Scr. Mater. 69, 409. (2013).

29. C. Garcia-Mateo, J.A. Jimenez, H.-W. Yen, M.K. Miller, L. Morales-Rivas, M. Kuntz, S.P. Ringer, J.-R. Yang, and F.G. Caballero, Acta Mater. 91, 162. (2015).

30. C.N. Hulme-Smith, M.J. Peet, I. Lonardelli, A.C. Dippel, and H.K.D.H. Bhadeshia, Mater. Sci. Technol. 31, 254. (2015).

31. H.K.D.H. Bhadeshia, Philos. Mag. 93, 3714. (2013).

32. J.H. Jang, H.K.D.H. Bhadeshia, and D.-W. Suh, Scr. Mater. 68,195 . (2013).

33. A. Navarro-López, J. Hidalgo, J. Sietsma, and M.J. Santofimia, Mater. Charact. 128, 248. (2017).

34. A. Navarro-López, J. Sietsma, and M.J. Santofimia, Metall. Mater. Trans. A 47, 1028. (2016).

35. D. Kim, S.-J. Lee, and B.C. De Cooman, Metall. Mater. Trans. A 43, 4967. (2012)

36. S.M.C. van Bohemen, M.J. Santofimia, and J. Sietsma, Scr. Mater. 58, 488. (2008).

37. A.M. Ravi, A. Navarro-López, J. Sietsma, and M.J. Santofimia, Acta Mater. 188, 394. (2020).

38. S.M. Hasan, S. Kumar, D. Chakrabarti, and S.B. Singh, Philos. Mag. 100, 797. (2020).

39. D.J. Dyson, J. Iron Steel Inst. 208, 469. (1970).

40. P. Jacques, E. Girault, T. Catlin, N. Geerlofs, T. Kop, S. van der Zwaag, and F. Delannay, Mater. Sci. Eng. A 273-275, 475. (1999).

41. C. Garcia-Mateo, F.G. Caballero, M.K. Miller, and J.A. Jimenez, J. Mater. Sci. 47, 1004. (2012).

42. I. Pushkareva, B. Shalchi-Amirkhiz, S.Y.P. Allain, G. Geandier, F. Fazeli, M. Sztanko, and C. Scott, Metals 10, 392. (2020).

43. S.S. Babu, E.D. Specht, S.A. David, E. Karapetrova, P. Zschack, M. Peet, and H. Bhadeshia, Metall. Mater. Trans. A 36, 3281. (2005).

44. S. Allain, G. Geandier, J.-C. Hell, M. Soler, F. Danoix, and M. Gouné, Metals 7, 232. (2017).

45. S.Y.P. Allain, S. Gaudez, G. Geandier, J.-C. Hell, M. Gouné, F. Danoix, M. Soler, S. Aoued, and A. Poulon-Quintin, Mater. Sci. Eng. A 710, 245. (2018).

46. C. Zener, Trans Aime 167, 550. (1946).

47. J.W. Christian, Mater. Trans. JIM 33, 208. (1992).

48. Y. Lu, H. Yu, and R.D. Sisson, Mater. Sci. Eng. A 700, 592. (2017).

49. Z. Nishiyama, Martensitic Transformation (Elsevier, 2012),

50. C.S. Roberts, JOM 5, 203. (1953).

51. R. Rementeria, J.D. Poplawsky, M.M. Aranda, W. Guo, J.A. Jimenez, C. Garcia-Mateo, and F.G. Caballero, Acta Mater. 125, 359. (2017).

52. P. Maugis, Comput. Mater. Sci. 159, 460. (2019).

53. P. Maugis, D. Connétable, and P. Eyméoud, Scr. Mater. 194, 113632. (2021).

54. R. Ranjan, and S.B. Singh, Acta Mater. 202, 302. (2021).

55. F.G. Caballero, M.K. Miller, C. Garcia-Mateo, J. Cornide, and M.J. Santofimia, Scr. Mater. 67, 846. (2012).

56. F.G. Caballero, M.K. Miller, and C. Garcia-Mateo, Acta Mater. 58, 2338. (2010).

57. J. Tian, G. Xu, Z. Jiang, M. Zhou, H. Hu, and Q. Yuan, ISIJ Int. 58, 1875. (2018).

58. X.L. Wang, K.M. Wu, F. Hu, L. Yu, and X.L. Wan, Scr. Mater. 74, 56. (2014).

Publisher's Note Springer Nature remains neutral with regard to jurisdictional claims in published maps and institutional affiliations. 